\title{
The adolescent varicocele: Attempting to de-muddify the fuzzification ${ }^{1}$
}

\author{
Andrew MacNeily, MD
}

Department of Urologic Sciences, University of British Columbia, Vancouver, BC, Canada

Cite as: Can Urol Assoc J 2017;11 (1-2Suppl1):S40. http://dx.doi.org/10.5489/cuaj.4348

See related article on page S34.

$\mathrm{S}$ igh. That's what I do before entering the room to see a new referral for the adolescent with a varicocele. They are often referred as a "scrotal mass" or "testicular tumour," which leads to family anxiety and a trip to Dr. Google before seeing me. Alternatively, they are an incidental finding on an ultrasound done for some nonspecific symptoms. I then explain to the family that $15 \%$ of the normal male population will have a varicocele; that lots of men see a urologist requesting a vasectomy after having produced two or three kids, and when examined they have a varicocele. But yes, they are more common in adult men who present with a fertility problem. A dialogue then ensues:

"So, should my son have surgery?"

"Er, sometimes, maybe, it depends."

"What does that mean?"

"Well...we offer intervention if the testicle seems to be not growing at the same pace as the other side, except that can happen normally during adolescence even without a varicocele."

"What about a sperm sample?" (blush)

"We could try that, but we don't really know what the norms are for adolescents."

"What about some blood hormone tests, doc?"

"They don't help much either, unfortunately."

"Is my son going to have trouble producing kids in the future if we do nothing about this thing?"

"Not necessarily. There is no proof that paternity rates are higher in those who have surgery compared to those who do not."

"So what does surgery look like?"

"We could make an incision in the groin and tie off the veins, or cut a little higher up and do the same thing, or we could stick a telescope in the belly button and put a clip on the enlarged vein(s), or we could ask a radiologist to put a needle in the big vein in the neck and squirt some glue or metal coils to block the enlarged veins from inside."

"Mmmm.....I don't like the sound of that. What are the complications?"

"Well, the procedure could fail; in fact your son will probably still have some biggish veins on that side no matter what is done. He could develop fluid around the testicle or, in rare cases, the testicle could wither away after surgery."

"I see. How about we follow this along and see how things progress?"

"Good idea! Let's do a physical exam and an ultrasound every once in a while over the next few years just to keep an eye on that testicle. I can always do the surgery, but it is hard to undo."

"OK, sounds good, but is ultrasound and physical examination accurate?"

"Well not really.... but it is the best we have"

"You don't seem to know anything very definitive about varicoceles, doc!"

"Correct. See you in six months."

And so it goes. The authors have done an excellent job of summarizing the literature on what, to me, has always been a nebulous topic. It is not surprising that definitive recommendations are difficult to draw from this review. Nonetheless, the authors should be congratulated for their efforts.

Competing interests: The author reports no competing personal or financial interests.

This paper has been peer-reviewed.

\section{Reference}

1. Fotheringham, Allan. In: Last Page First. Key Porter Books. 1999.

Correspondence: Dr. Andrew MacNeily, Department of Urologic Sciences, University of British Columbia, Vancouver, BC, Canada; amacneily@cw.bc.ca 